\title{
BMJ Global Health Global health degrees: at what cost?
}

\author{
Anita Svadzian, ${ }^{1}$ Nathaly Aguilera Vasquez, ${ }^{1}$ Seye Abimbola (D) , ${ }^{2}$ \\ Madhukar Pai (1D) ${ }^{1}$
}

To cite: Svadzian $A$, Vasquez NA, Abimbola S, et al. Global health degrees: at what cost?BMJ Global Health 2020;5:e003310. doi:10.1136/ bmjgh-2020-003310

Received 1 July 2020 Accepted 1 July 2020

Check for updates

\section{(c) Author(s) (or their} employer(s)) 2020. Re-use permitted under CC BY-NC. No commercial re-use. See rights and permissions. Published by BMJ.

${ }^{1}$ Epidemiology \& Biostats, McGill University, Montreal, Quebec, Canada

${ }^{2}$ School of Public Health, University of Sydney, Sydney, New South Wales, Australia

Correspondence to

Dr Madhukar Pai;

madhukar.pai@mcgill.ca
In theory, global health, as a field, takes pride in principles such as equity, fairness, reciprocity and bidirectional partnerships. ${ }^{1}$ In practice, many aspects of global health are dominated by individuals and institutions in high-income countries (HICs) who seem to benefit more than their counterparts in low-income and middle-income countries (LMICs).$^{2-4}$ Global health organisations are mostly head-quartered in HICs, and run by people, primarily men, from HICs. ${ }^{45}$ Further, authorship of global health publications is dominated by people in HICs, ${ }^{6-8}$ as well as editorial boards of global health journals. ${ }^{9} 10$

What about global health education? In the past two decades, global health has become very popular among students in HICs. In response to higher demand and availability of increased funding, many HIC universities invested heavily in global health programmes. ${ }^{11}$ Although dozens of degree programmes in global health emerged as a consequence, it remains unclear who the target audience really is, and what it might cost to earn one of these degrees. Are these degree programmes aimed at LMICs, where training gaps are enormous, ${ }^{12}$ or are they primarily for the benefit of HIC trainees and institutions?

To answer this question, we identified academic programmes that offer either a Master's of Global Health or a Master's of International Health degree. We used the Academic Global Health Programmes database maintained by the Consortium of Universities for Global Health $(\mathrm{CUGH}),{ }^{11}$ supplemented by online searches for universities not included in the CUGH list (see box 1 for details). We focused on Master's of Global or International Health programmes (on campus or online), rather than related degrees such as Master's of Public Health (MPH) which might offer global health concentrations, options or tracks.

In all, out of 45 Global or International Health Master's degrees identified, we were able to gather information for 41 degree programmes, as of March 2020. Table 1 outlines details for each degree programme considered for this analysis. As shown in figures $1,17(42 \%)$ were located in North America, $19(46 \%)$ in Europe, $2(5 \%)$ in Western Pacific, $2(5 \%)$ in Asia and 1 (2\%) Africa. Nineteen $(46 \%)$ of the degree programmes were 1-year programmes, and the rest could be completed over a longer period. Of the 41 degree programmes, five (12\%) were entirely on-line (distance education), while the rest were on-campus.

Results for average tuition fees for Master's degrees in global or international health are displayed in table 2. On average, across all 41 degree programmes, the mean tuition fee was US \$41 790 for international students-usually defined as students who undertake studies outside their country of residence-and US\$33 603 for domestic students-usually defined as students who undertake studies in a country where they hold citizenship or other documented residency status.

Most programmes in our analysis (95\%) were based in HICs, with an average tuition of US\$37 732. The mean tuition fee for online-option degrees (degrees which can be completed either in part or in full away from the traditional campus setting) was US\$19 353 vs US\$40 244 for on-campus programmes. On average, tuition for programmes in privately funded schools were considerably higher than for public schools, US\$69 446 and US\$19 379, respectively.

For the 16 programmes in the USA, the average tuition fee for all students was US\$68 093. There was little difference between domestic and international student fees (US $\$ 67461$ for domestic vs US $\$ 68724$ for international students). For programmes in the UK, the average tuition fee was US $\$ 14$ 104 for domestic vs US\$25 468 for international students. In Nordic countries (i.e., Sweden and Norway), the tuition was US $\$ 0$ for domestic students but an average of US\$34 354 for international students. Interestingly, the degree programmes in Asia and 
Box 1 Lack of transparency: the approach and limitations to our analysis

Data were extracted by two authors (AS and NAV) with any discrepancies in double entry agreed on by consensus. For each degree programme we identified, we visited websites of these programmes and collected data on the tuition fees for international versus domestic applicants. We also emailed coordinators of the degree programmes to request clarifications or additional data, if needed.

We focused on tuition fees for the entire degree programme rather than the annual tuition fees, since duration of degree programme varied from 1 to 3 years, with some degrees structured in such a way that students' graduation time was tied to their experiences and training garnered prior to programme entry. Thus, it should be noted that when the final cost was calculated this was based on the typical time to graduation indicated either on the website itself or by the respective school's programme coordinator. In most European schools, fees are fixed regardless of how long a student takes to complete their degree. However, in North America time to graduation can be quite variable and students usually pay tuition for each semester or credit. This is particularly true of the US system where a degree cost can vary substantially between students. We chose to calculate total tuition based on a typical student's experience as suggested by either the school's website or the coordinator.

In addition, some programmes require a project (eg, summer practicum) be conducted in elsewhere (typically, a low-income and middle-income countries (LMIC) - the costs for these were not always absorbed by the tuition fees. While some students had their costs for projects abroad covered by a supervisor and others could apply for scholarships, the remainder would have to pay for the additional costs out of pocket. This information was not transparent across degree programmes.

Given the difficulty in collecting data on tuition itself, we did not quantify cost of living directly for each school. Rather, we aimed to account for differences in living costs for any given school using an adjustment measure used by the International Civil Service Commission (ICSC), established by the United Nations (UN). ${ }^{22}$ The UN postadjustment system is designed to ensure that the net remuneration pay of UN staffers garners an equivalent purchasing power to that same staffer at the base of the system, New York City, regardless of their posting location. Post adjustment multiplier considers differences in prices between the city in question and New York; local inflation; exchange rate of local currency relative to the USD; and average expenditure pattern of staff members currently at a given location. The multiplier is adjusted periodically to reflect changes in the cost of living in a given city. We used the multiplier from the March 2020 update. All cost information was converted into US dollars using the ICSC conversion factor (March 2020 update) to make international comparisons possible.

Our analysis has several limitations. First, although we did an extensive search, it is possible we missed a few degree programmes. Our search was limited to schools which were explicitly Master's of Global or International health rather than Master's programmes with an option of a global health concentration. Future iterations of this analysis could include other types of global health degrees (eg, Master's of Public Health with a global health concentration).

Second, while efforts were made to contact each school if the tuition was not clearly listed on their webpage, it is possible that errors were made when calculating the tuition for fluctuating fees (eg, based on number of credits where the per-credit fee changes each year). For programmes which did not have a fixed total fee, it was difficult to gauge exactly how much a degree would cost in its entirety and despite seeking clarification, many schools could not give an exact number. In addition, while tuition was calculated based on the fees posted on a school's website in March 2020 , fees may have changed for the Fall 2020 cohort. There was a lack of transparency both on the websites themselves and after contacting the universities. In addition, many programmes were reluctant to disclose the exact duration of a degree, since the duration depended largely on the profile of the incoming trainee and how quickly they could meet programme requirements.

Third, we used a simplistic marker for cost for living established by the UN. While it would have been ideal to have gathered information of the average cost of living for a typical student in any given year, this information was not usually available for most schools, with some exceptions. Fourth, we could not get data on diversity of the students who are in these global health degree programmes. Thus, we do not know what proportion of the student body is made up of high-income country versus LMIC trainees. Lastly, we also do not have data on how many LMIC trainees receive tuitionfee waivers or scholarships to complete global health degrees.

Africa were associated with a high cost, with the Master's in Global Health Delivery in Rwanda costing US\$54 000, and degrees in Asia costing, on average US\$17 500 .

As previously mentioned, there is a large divide between tuition fees at public vs private institutions. This is underscored by the fact that the least expensive programme was at the University of Bergen where tuition fee is US $\$ 0$ since, as stated on their webpage, public universities in Norway do not charge students tuition fees, regardless of the student's country of origin. It is within their mandate as an institution and part of the country's general ethos to provide quality education to its students and future leaders at no cost. This philosophy is quite different from their counterparts in the USA where 13 of the 15 private schools are located and where the most expensive programme identified is based at Duke University (US\$126 334).

Table 3 compares the tuition fees for domestic vs international students. It shows that on average $\mathrm{HIC}$ programmes charged higher fees for international students (1.3 times higher on average), while LMIC countries charged the same for both international and domestic students. However, by looking at table 1, it can be noted that American schools generally charged the same for both categories of students.

Figure 2 provides data on relative costs of living in each location as a function of the cost of attendance for international versus domestic students. Using the United Nations postadjustment multiplier as a proxy for cost of living, the scale of the circles is relative to the cost of living of each city; smaller circles represent locations that are less expensive to live in relative to its headquarters in New York City. While cost of living is relatively expensive for many European locations, these costs are offset by less expensive tuition fees. The same cannot be said about North American schools; many are located in cities with similarly high costs of living, yet tuition fees are much higher than for European schools. Figure 2 


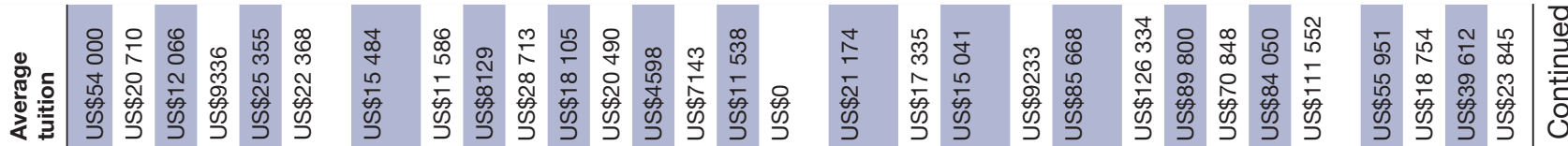

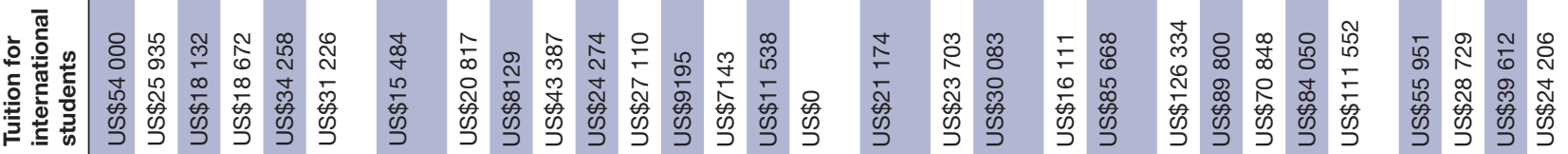

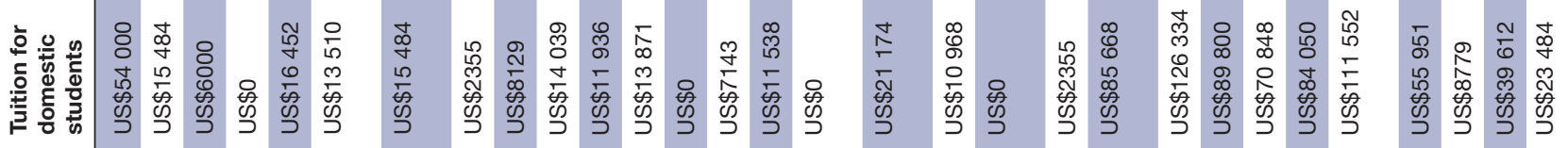

蒂

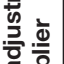

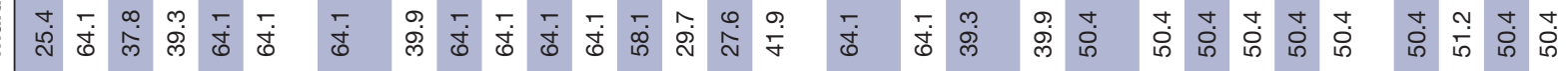

政

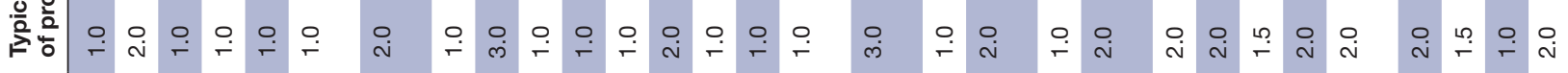

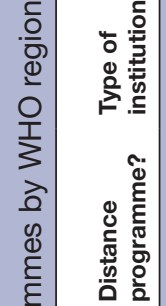

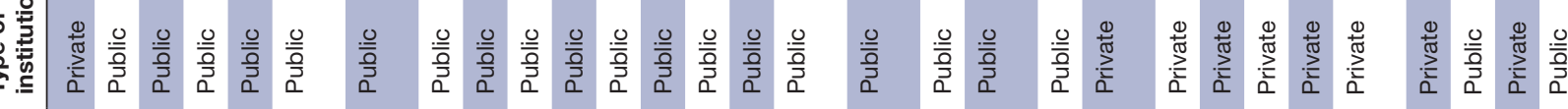

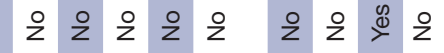

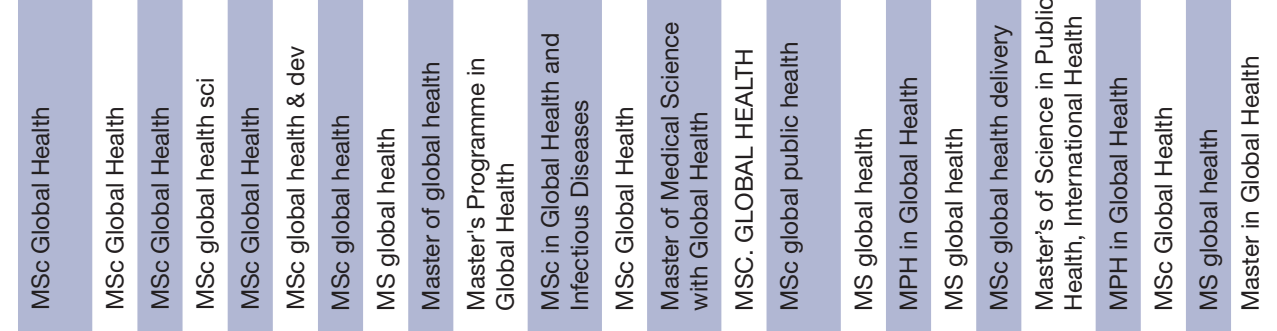

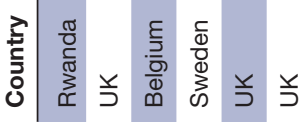

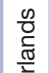

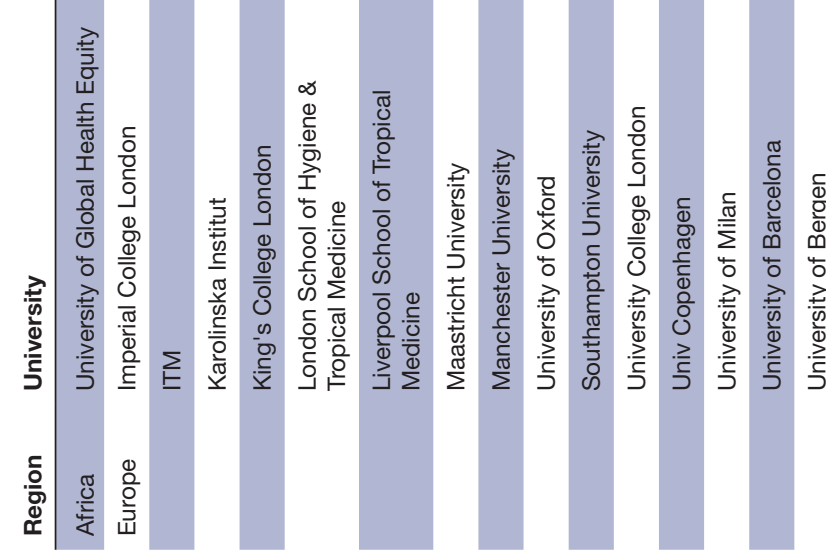

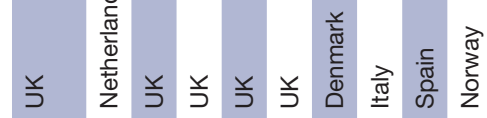

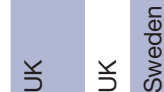

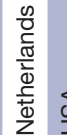
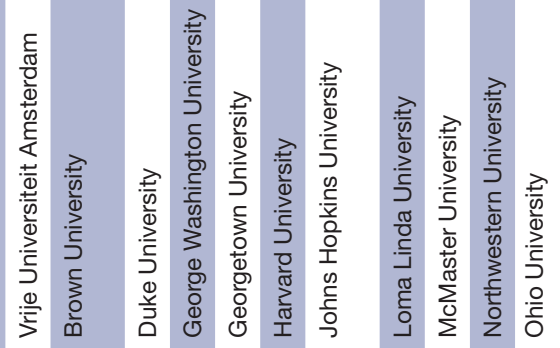


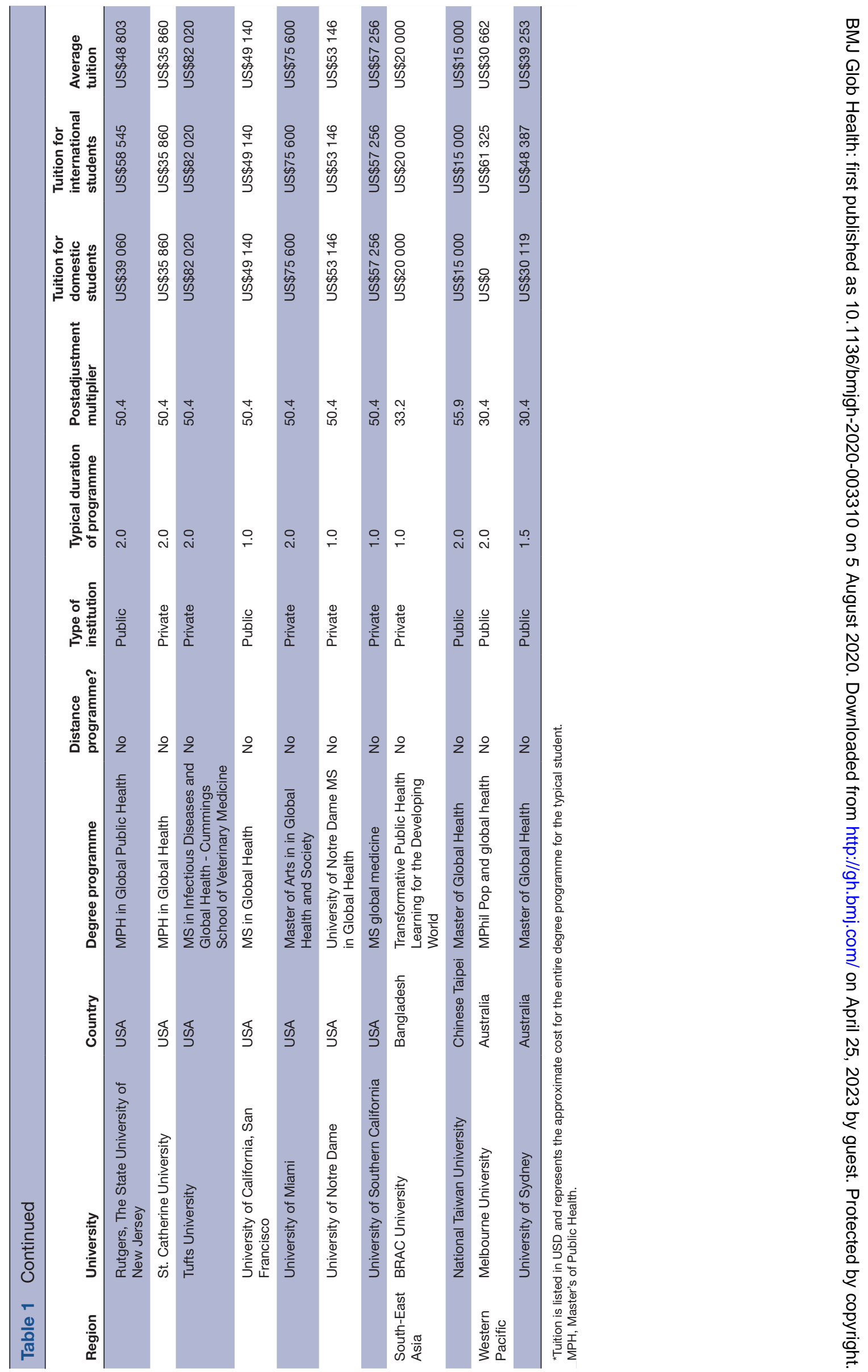




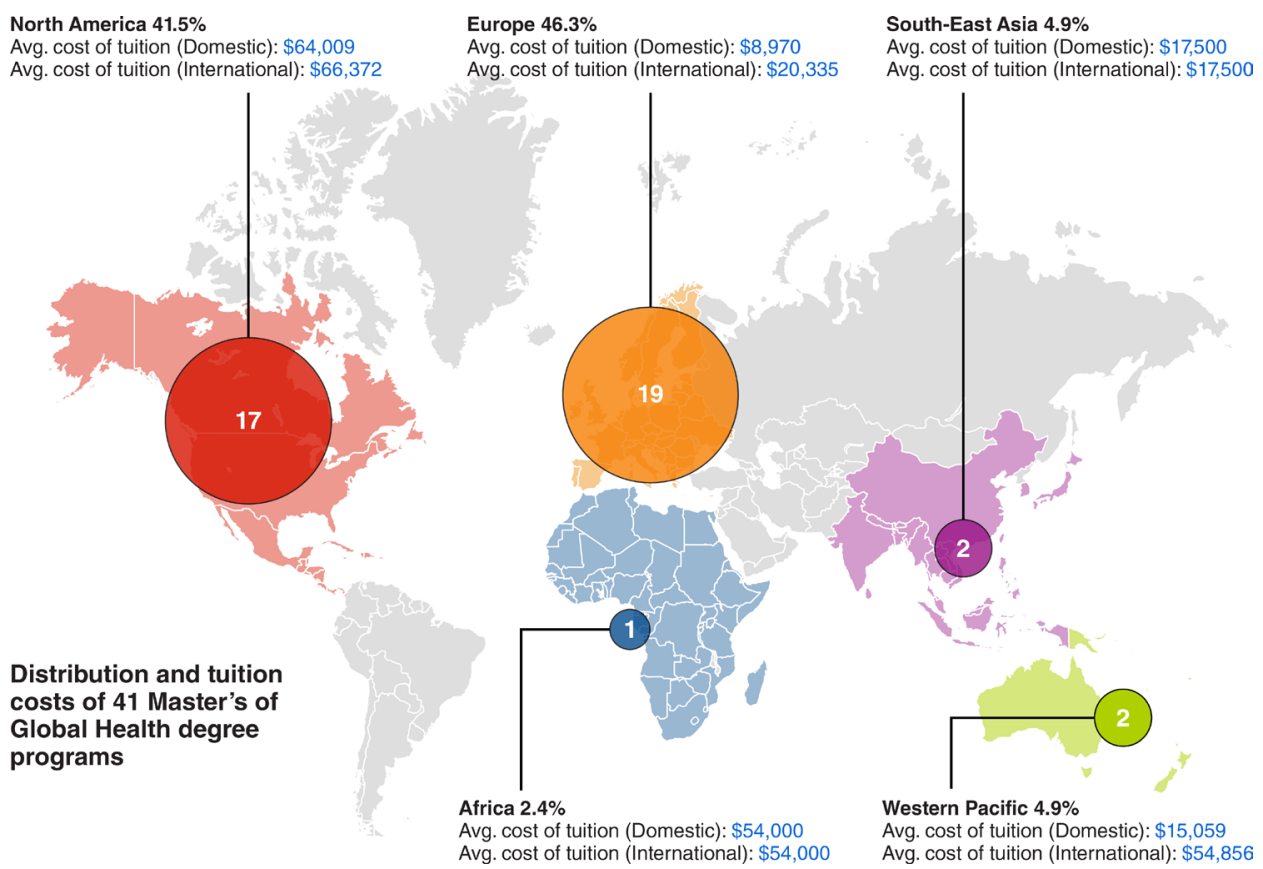

Figure 1 Geographical distribution of Master's degrees in global or international health, and mean tuition costs for the entire degree in USD $(n=41)$.

also shows that many schools charge the same amount to domestic and international students (with the exception of Western Pacific and Nordic schools), and that there is a wide dispersion in costs of tuition by region.

Despite limitations (see box 1), we can make some key inferences from this analysis. The data presented suggest that there may be a disconnect between where global health training is needed most versus where the degree programmes are currently offered. It would thus be useful to apply the health labour market framework to better understand this discrepancy between demand and supply and the mechanisms behind this apparent divide. ${ }^{13}$ One potential explanation for this disconnect is that the idea of 'global health training' is itself an HIC phenomenon; much of what is taught in such programmes in HICs are likely typically covered in MPH and related programmes (eg, community health) in LMICs. ${ }^{3}{ }^{1415}$ Another explanation, which we discuss later, is that global health degrees are a revenue-generating activity for the universities, which seek to take advantage of growing student interest in global health.

Tuition fees are high for most programmes. These costs will be even higher if we added costs beyond tuition (eg, travel, living expenses, accommodation, health insurance and summer practicum). Without substantial external support, these degrees, we believe, would be unaffordable to trainees in LMICs. Additional research is needed to calculate fully loaded costs for global health degrees. This would vary a lot, depending on the country and cost of living and what financial aid or fellowships

Table 2 Average tuition fees for Master's Degree in Global or International Health, by subgroup (USUS\$)

\begin{tabular}{|c|c|c|c|c|c|}
\hline & \multicolumn{4}{|c|}{ Average Tuition fees by subgroup (US\$) } \\
\hline & & $\mathbf{N}(\%)$ & Mean & Minimum & Maximum \\
\hline \multirow{2}{*}{ Student status } & Domestic tuition & - & US\$33 603 & US\$0 & US\$126 334 \\
\hline & International tuition & - & US $\$ 41790$ & US\$0 & US\$126334 \\
\hline \multirow[t]{2}{*}{ Country income } & High-income country & $39(95.1)$ & US\$37 732 & US\$O & US\$126 334 \\
\hline & $\begin{array}{l}\text { Low-income and middle-income } \\
\text { country }\end{array}$ & $2(4.9)$ & US\$37000 & US\$20000 & US\$54 000 \\
\hline \multirow[t]{2}{*}{ Online option } & Yes & $5(12.2)$ & US\$19 353 & US\$7143 & US\$39 612 \\
\hline & No & $36(87.8)$ & US\$40 244 & US\$0 & US\$126334 \\
\hline \multirow[t]{2}{*}{ Duration of course } & Short ( $\leq 1$ year) & $19(46.3)$ & US\$24 549 & US\$0 & US\$57 256 \\
\hline & Long (>1 year) & $22(53.6)$ & US\$49052 & US\$4598 & US\$126334 \\
\hline \multirow[t]{2}{*}{ Type of school } & Private & 15 (36.5) & US\$69 446 & US\$20000 & US\$126 334 \\
\hline & Public & $26(63.4)$ & US\$19 379 & US\$0 & US\$49 140 \\
\hline
\end{tabular}


Table 3 Average tuition fees for domestic versus international students in Master's Degree in Global or International Health, by subgroup (USUS\$)

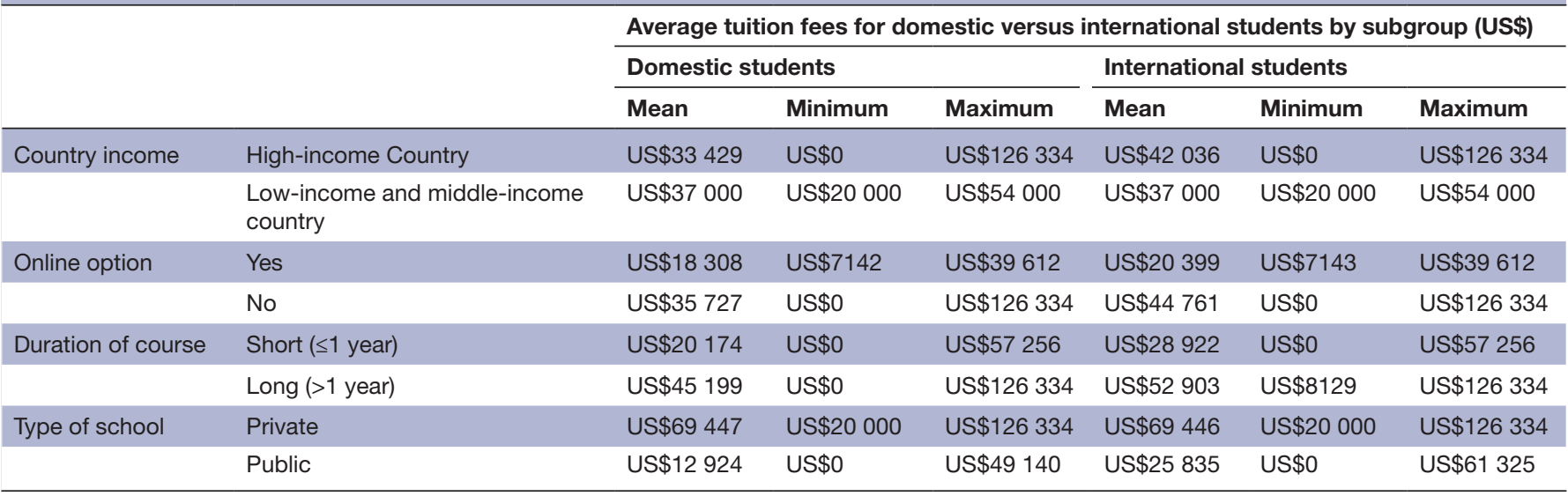

are available to students from LMICs to mitigate these costs.

To this extent, we hope global health degree programmes will be transparent about diversity in their student body and provide information on what proportion of their LMIC students receive tuition waivers or fellowships. We need data on diversity among global health students. We also need data on what proportion of the LMIC students in these degrees get full tuition fee waivers. We know almost all schools offer such fee waivers, but cannot provide data on how many. This could be a topic of future research. Tracking and

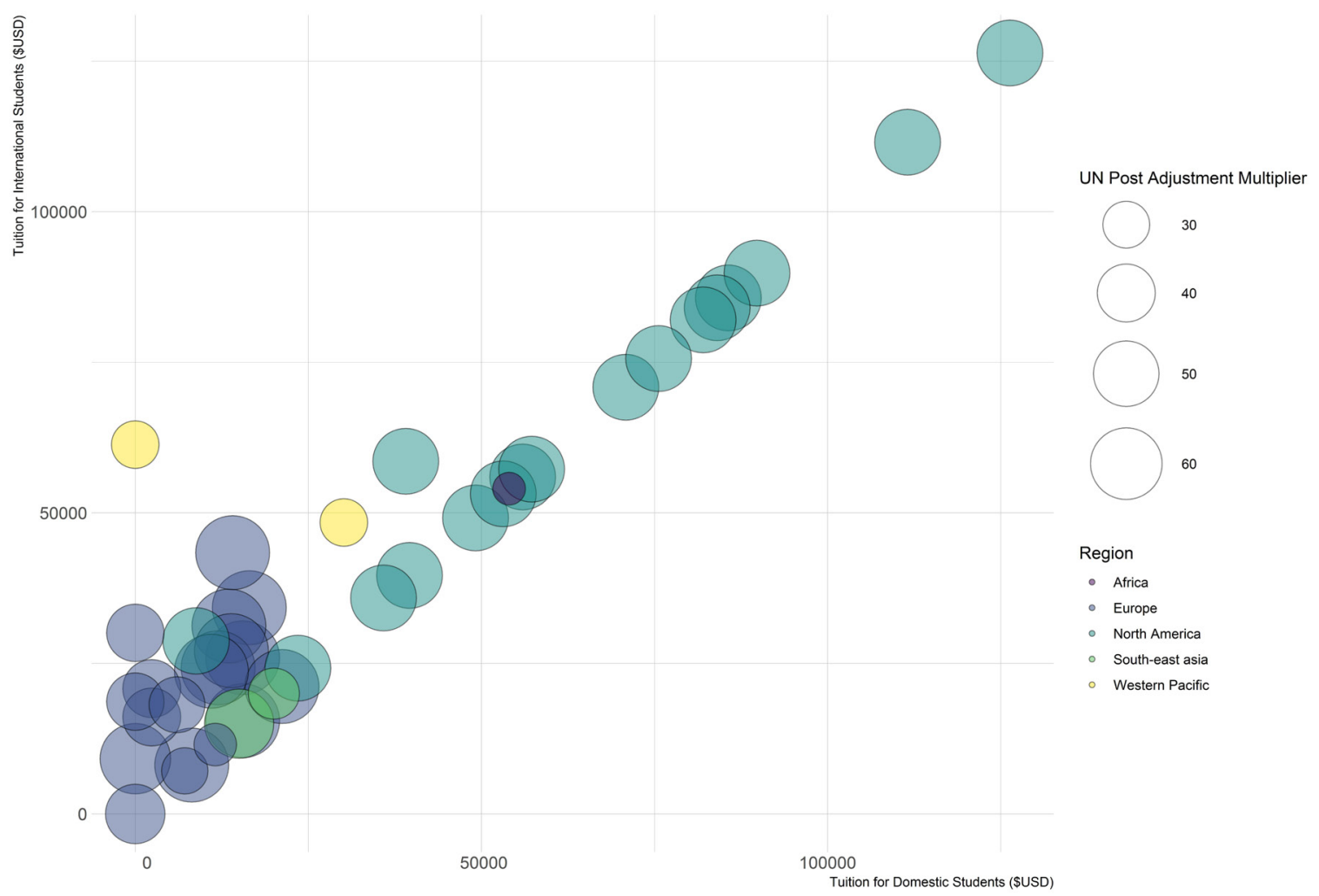

Figure 2 International versus domestic tuition fees for Master's of Global or International Health Programmes by region and scaled to account for cost of living as per the UN postadjustment multiplier. UN postadjustment multiplier is a measure of relative cost of living used to reflect changes in the cost of living in a given duty station/city as compared with New York city. The scale of the bubbles in the graph above are proportional to their relative size for this indicator and are colour coded by WHO Region. The bubbles lie in the plane in relation to their contribution to domestic versus international tuition, respectively, with programmes where the $\mathrm{X}$-axis equally the $\mathrm{Y}$-axis in a diagonal line, connoting an equivalence between costs for international and domestic students. UN, United Nations. 
improving this could help enhance reciprocity in global health. ${ }^{16}$

If students are paying high fees to get global health degrees, it is unclear what their job prospects are after completing such degrees. To recover the costs, they would need to find high-paying jobs (which might not be in the field of global health) and/or work in HICs. We need to further study whether and to what extent global health degrees actually help build global health capacity and address the massive healthcare workforce shortage in LMICs. ${ }^{12}$

In making the decision on fee waiver, another consideration should be the provenance of global health knowledge. The cost of global health training programmes for LMIC students should reflect the fact that LMICs are the origin of much of the knowledge that gets shared (or should ideally be shared) in HIC global health training programmes. ${ }^{6}$ This is one of many reasons why LMIC candidates should, as a matter of fairness, receive fee waivers. Fee waivers may also represent a form of reparation, given the colonial and extractive origins of many HIC universities and global/ public health schools. ${ }^{1718}$

Based on where global health degrees are offered and the high fees charged, we infer that most degrees might be catering to HIC students and students from elite and privileged backgrounds in LMICs, thus privileging a student group that is already privileged. The current leaders of global health organisations are drawn from this same limited pool. ${ }^{5}$ The pattern of global health training serves to perpetuate lack of diversity, a huge problem in global health that risks perpetuating colonial approaches and structures. ${ }^{419}$

If global health schools in HICs truly care about making global health training accessible to LMICs and believe in equity and reciprocity, then we should expect to see tiered tuition fee structures. We found that most schools, especially those in the USA, charge the same for domestic and international students, suggesting a lack of lower and affordable pricing for LMIC trainees. This may be because the degree programmes are meant to generate revenues and be 'self-supporting' or 'self-financing.' But this explanation also suggests that, contrary to using global health degrees to enhance equity and reciprocity, many HIC universities, especially medical schools, (including private universities with billions in endowments) apparently see global health training as a mechanism to generate revenue.

To democratise global health education and improve equity, fairness and reciprocity, HIC universities can and must allocate a certain proportion of their slots for LMIC students, offer full funding support (including accommodation), and support with travel and visas. The Fogarty International Center training programmes by the US National Institutes of Health (NIH) is a good model for all HICs to replicate, as it has helped train over 6000 scientists worldwide, spending a small fraction of the overall NIH budget. ${ }^{20}$
We are not surprised that there are few degree programmes in global health in LMICs, since nationals of LMICs do not see their day-to-day public health or clinical work as 'global health.' ${ }^{3}$ But we are puzzled as to why the few degree programmes based in Asia and Africa are priced so high. So, even within LMICs, these degree programmes may be serving the privileged and elite. While these schools have indicated that they offer scholarships to candidates from LMICs it is unclear how much funding is given to each student and how many students are granted these awards. This transparency would be useful.

Because of the COVID-19 pandemic, more global health degrees might move to remote or distance education. It is disappointing that distance education global health degrees still cost about US\$20 000 for international students. If tuition fees were more affordable for LMIC trainees, then thousands of students can be trained. But beyond affordability, there are other major barriers for LMIC trainees, including the struggle to get visas to enter countries such as the USA and UK, ${ }^{21}$ especially with Brexit and US visa bans. By working with LMIC experts to create affordable, quality, online training programmes for LMIC students, HIC universities can demonstrate that they can deliver on reciprocity and equity.

In conclusion, even if HIC universities made their degrees more accessible, we should still ask why an African trainee must go to London or Boston to learn about control of sleeping sickness or malaria (and pay top dollars for such training)? The traditional mindset in global health that expertise flows from North to South, is reflected in research, training, consultancy and technical assistance. This colonial model is ripe for disruption. Building top-notch institutions in LMICs is critical, to reduce dependence on HICs, and to improve the overall quality, depth and relevance of global health training and research. ${ }^{15}$ Someday, we hope HIC trainees will earn global health degrees from such LMIC universities, and learn directly from experts who are closest to the problems and closest to the solution.

Twitter Seye Abimbola @seyeabimbola and Madhukar Pai @paimadhu

Acknowledgements We are grateful to all the universities that responded to our request for information about their degree programmes in global health. Errors, if any, are our own.

Contributors MP and SA conceived the study. AS and NAV collected and verified the data. AS and MP wrote the initial draft. All authors revised and approved the final version.

Funding The authors have not declared a specific grant for this research from any funding agency in the public, commercial or not-for-profit sectors.

Disclaimer The depiction of boundaries on this map does not imply the expression of any opinion whatsoever on the part of BMJ (or any member of its group) concerning the legal status of any country, territory, jurisdiction or area or of its authorities. This map is provided without any warranty of any kind, either express or implied.

Competing interests MP is on the editorial board of BMJ Global Health. SA is editor-in-chief of BMJ Global Health. They are from India and Nigeria, respectively, but had the privilege of training in HIC universities. They are currently based in HIC universities, and are aware of their obligation to address the inequities discussed in this paper.

Patient consent for publication Not required.

Provenance and peer review Not commissioned; internally peer reviewed. 
Data availability statement All relevant data are contained in Table 1 with nothing more to share.

Open access This is an open access article distributed in accordance with the Creative Commons Attribution Non Commercial (CC BY-NC 4.0) license, which permits others to distribute, remix, adapt, build upon this work non-commercially, and license their derivative works on different terms, provided the original work is properly cited, appropriate credit is given, any changes made indicated, and the use is non-commercial. See: http://creativecommons.org/licenses/by-nc/4.0/.

\section{ORCID iDs}

Seye Abimbola http://orcid.org/0000-0003-1294-3850

Madhukar Pai http://orcid.org/0000-0003-3667-4536

\section{REFERENCES}

1 Koplan JP, Bond TC, Merson MH, et al. Towards a common definition of global health. Lancet 2009;373:1993-5.

2 Pai M. Global health research needs more than a Makeover. USA: Forbes, 2019. https://www.forbes.com/sites/madhukarpai/2019/ 11/10/global-health-research-needs-more-than-a-makeover/\# 3c21ddcf7e34

3 Abimbola S. On the meaning of global health and the role of global health journals. Int Health 2018;10:63-5.

4 Pai M. Global Health Needs To Be Global \& Diverse. USA: Forbes, 2020. https://www.forbes.com/sites/madhukarpai/2020/03/08/ global-health-needs-to-be-global-diverse/\#502c7d976590

5 Global Health 50/50. The global health 50/50 report 2020: power privilege and priorities. London, UK, 2020. https://globalhealth5050. org/2020report/

6 Abimbola S. The foreign gaze: authorship in academic global health BMJ Glob Health 2019;4:e002068.

7 Hedt-Gauthier BL, Jeufack HM, Neufeld NH, et al. Stuck in the middle: a systematic review of authorship in collaborative health research in Africa, 2014-2016. BMJ Glob Health 2019;4:e001853.

8 Mbaye R, Gebeyehu R, Hossmann S, et al. Who is telling the story? A systematic review of authorship for infectious disease research conducted in Africa, 1980-2016. BMJ Glob Health 2019;4:e001855.
9 Bhaumik S, Jagnoor J. Diversity in the editorial boards of global health journals. BMJ Glob Health 2019;4:e001909.

10 Nafade V, Sen P, Pai M. Global health journals need to address equity, diversity and inclusion. BMJ Glob Health 2019;4:e002018.

11 Consortium of Universities for Global Health. Academic global health programs. Washington, DC: CUGH, 2020. https://www.cugh.org/ programs

12 World Health Organization. The labour market for human resources for health in low- and middle-income countries. Geneva: WHO, 2012.

13 Sousa A, Scheffler RM, Nyoni J, et al. A comprehensive health labour market framework for universal health coverage. Bull World Health Organ 2013;91:892-4.

14 Horton R. Offline: the case against global health. The Lancet 2014;383:1705

15 R. Montenegro C, Bernales M, Gonzalez-Aguero M. Teaching global health from the South: challenges and proposals. Crit Public Health 2020;30:127-9.

16 Pai M. Reciprocity in global health: here is how we can do better. Forbes. USA: Forbes, 2020. https://www.forbes.com/sites/ madhukarpai/2020/03/06/reciprocity-in-global-health-here-is-howwe-can-do-better/\#4a9da6e677a9

17 Richardson ET. On the coloniality of global public Heath. Medicine Anthropology Theory 2019;6:101-18.

18 Richardson ET, McGinnis T, Frankfurter R. Ebola and the narrative of mistrust. BMJ Glob Health 2019;4:e001932.

19 Pai M. Global health still mimics colonial ways: here's how to break the pattern, 2019. Available: https://theconversation.com/globalhealth-still-mimics-colonial-ways-heres-how-to-break-the-pattern121951

20 Fogarty International Center. Our role in global health. Bethesda: National Institutes of Health, 2020. https://www.fic.nih.gov/About/ Pages/role-global-health.aspx

21 The Lancet global H. Passports and privilege: access denied. The Lancet Global health 2019;7:e1147.

22 International Civil Service Commission. The post adjustment index. New York: ICSC, 2020. https://icsc.un.org/Home/PostAdjustment 